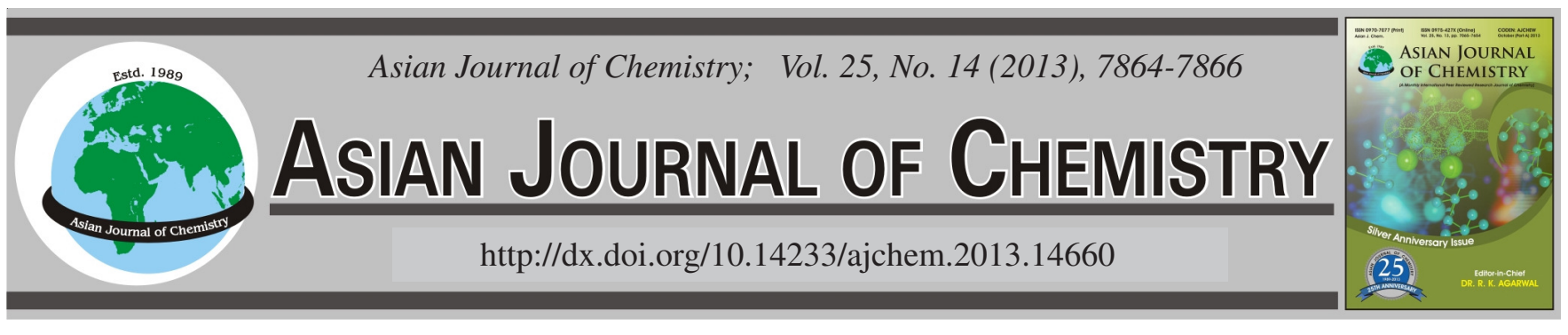

\title{
Phosphomolybdic Acid Catalyzed Synthesis of 13-Aryl-5H-dibenzo[b,i]-xanthene-5,7,12,14(13H)-tetraones
}

Di Liu ${ }^{*}$, Shixue Zhou, Jun GaO and Dongmei Xu

College of Chemical and Environmental Engineering, Shandong University of Science and Technology, Qingdao 266590, Shandong, P.R. China *Corresponding author: Tel: +86 532 860577-98; E-mail: Ld002037132@163.com

A simple and facile synthesis of 13 -aryl-5H-dibenzo[b,i]xanthene-5,7,12,14(13H)-tetraones is accomplished by the one-pot condensation of 2-hydroxy-1,4-naphthaquinone and aldehydes under solvent-free condition in the presence of phosphomolybdic acid. This method has the advantages of high yield, clean reaction, short reaction time and simple work-up.

Key Words: 2-Hydroxy-1,4-naphthoquinone, Aldehydes, Phosphomolybdic acid, Solvent-free, Synthesis.

\section{INTRODUCTION}

2-Hydroxy-1,4-naphthaquinone is known for the past 4000 years, found in many natural products and has been employed as a synthetic intermediate for the preparation of numerous heterocyclic compounds with interesting biological properties such as antitumor, antibacterial, antifungal and antiinflammatory agents ${ }^{1-3}$. Xanthenes containing heterocyclic quinone group represent an important class of biologically active molecules ${ }^{4}$. Furthermore, these heterocycles display useful spectroscopic properties and are used as dyes ${ }^{5}$ as well as in laser technologies ${ }^{6}$. Thus, the development of new and simple synthetic methods for the efficient preparation of 13aryl-5H-dibenzo[b,i]xanthene-5,7,12,14(13H)-tetraones is of continuing interest.

According to current report, the synthesis reaction of 13aryl-5H-dibenzo[b,i]xanthene-5,7,12,14(13H)-tetraones by the one-pot condensation of 2-hydroxy-1,4-naphthaquinone and aldehydes has been improved in the presence of a catalyst, such as $p$-toluene sulfonic acid $^{7,8}$, ionic liquid ${ }^{9-11}$. Even though various procedures were reported, disadvantages including prolonged reaction times, laborious work-up procedures, use of an excess of expensive reagents/catalysts and use of toxic organic solvents necessitate the development of an alternative route for the synthesis of xanthene derivatives.

Heteropolyacids have found numerous applications as useful and versatile acid catalyst for some acid-catalyzed reactions due to the super acidic properties of solid heteropolyacid. They are usually solids which are insoluble in non-polar solvents but highly soluble in polar ones. Furthermore, heteropolyacids have several advantages, including high flexibility in modifi- cation of the acid strength, ease of handling, environmental compatibility and non-toxicity and experimental simplicity ${ }^{12,13}$. In this paper, we investigate the synthesis of xanthene derivatives in the presence of heteropolyacids under solvent-free conditions (Scheme-I).

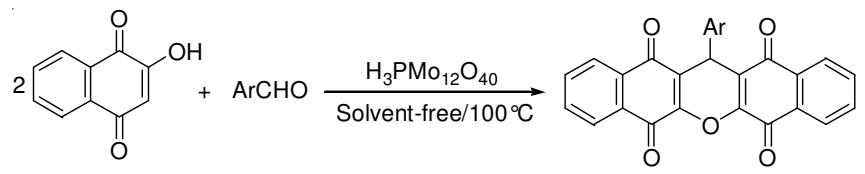

Scheme-I: $\quad$ Synthesis of 13-aryl-5H-dibenzo[b,i]xanthene-5,7,12,14(13H)tetraones

All reagents were of analytical grade and purchased from Sinopharm Chemical Reagent Co., Ltd. and were used without further purification.

General procedure for the synthesis of 13-aryl-5Hdibenzo[b, $\mathrm{i}]$ xanthene-5,7,12,14(13H)-tetraones: A mixture of aldehyde (5 mmol), 2-hydroxynaphthalene-1, 4-dione (10 $\mathrm{mmol})$ and $\mathrm{H}_{3} \mathrm{PMo}_{12} \mathrm{O}_{40}(0.25 \mathrm{mmol})$ was finely mixed together and heated at $100{ }^{\circ} \mathrm{C}$. The reaction was monitored by TLC. After completion, the reaction mixture was washed with cool ethanol and water. Further purification was followed by crystallization from ethanol.

\section{EXPERIMENTAL}

All the products are known compounds. The desired pure products were characterized by spectral (IR, ${ }^{1} \mathrm{H}$ NMR) and analytical data and by comparison of their physical and spectral data with those of known benzoxanthenes ${ }^{7,10}$. 
13-Phenyl-5H-dibenzo[b,i]xanthene-5,7,12,14(13H)tetraone (Table-1, entry 1). Red powder, m.p. 305-307 ${ }^{\circ} \mathrm{C}$; IR $\left(\mathrm{KBr}, \mathrm{v}_{\max }, \mathrm{cm}^{-1}\right): 3042,1705,1575,1280,745 ;{ }^{1} \mathrm{H}$ NMR $\left(\mathrm{DMSO}-d_{6}, 400 \mathrm{MHz}\right): \delta=5.14(\mathrm{~s}, 1 \mathrm{H}, \mathrm{CH}), 7.20-8.13(\mathrm{~m}$, $13 \mathrm{H}, \mathrm{Ar}$ ); anal. calcd. (\%) for $\mathrm{C}_{27} \mathrm{H}_{14} \mathrm{O}_{5}$ : C 77.51, H 3.37; found (\%): C 77.38, H 3.44.

TABLE-1

PREPARATION OF 13-ARYL-5H-DIBENZO[b, i]XANTHENE$5,7,12,14(13 H)$-TETRAONES CATALYZED BY $\mathrm{H}_{3} \mathrm{PMO}_{12} \mathrm{O}_{40}$

\begin{tabular}{clcc}
\hline Entry & \multicolumn{1}{c}{ Aldehyde } & Time (min) & Yield (\%) \\
\hline 1 & $\mathrm{C}_{6} \mathrm{H}_{5} \mathrm{CHO}$ & 100 & 84.3 \\
2 & $4-\mathrm{ClC}_{6} \mathrm{H}_{4} \mathrm{CHO}$ & 90 & 87.9 \\
3 & $4-\mathrm{BrC}_{6} \mathrm{H}_{4} \mathrm{CHO}$ & 100 & 84.8 \\
4 & $4-\left(\mathrm{CH}_{3}\right) \mathrm{C}_{6} \mathrm{H}_{4} \mathrm{CHO}$ & 100 & 80.7 \\
5 & $4-\mathrm{FC}_{6} \mathrm{H}_{4} \mathrm{CHO}$ & 90 & 86.2 \\
6 & $2-\mathrm{CH}_{3} \mathrm{OC}_{6} \mathrm{H}_{4} \mathrm{CHO}$ & 100 & 85.5 \\
\hline
\end{tabular}

13-(4-Chlorophenyl)-5H-dibenzo[b,i]xanthene-5,7,12,14(13H)-tetraone (Table-1, entry 2). Brown powder, m.p. 329$330{ }^{\circ} \mathrm{C}$; IR $\left(\mathrm{KBr}, v_{\max }, \mathrm{cm}^{-1}\right): 3016,1662,1614,829 ;{ }^{1} \mathrm{H}$ NMR (DMSO- $\left.d_{6}, 400 \mathrm{MHz}\right): \delta=5.12(\mathrm{~s}, 1 \mathrm{H}, \mathrm{CH}), 7.7 .30-8.11(\mathrm{~m}$, $12 \mathrm{H}, \mathrm{ArH}$ ); anal. calcd. (\%) for $\mathrm{C}_{27} \mathrm{H}_{13} \mathrm{O}_{5} \mathrm{Cl}: \mathrm{C} 77.61, \mathrm{H} 2.89$; found (\%): C 77.69, H 2.95.

13-(4-Bromophenyl)-5H-dibenzo[b,i]xanthene-5,7,12,14(13H)-tetraone (Table-1, entry 3). Brown powder, m.p. 333$335{ }^{\circ} \mathrm{C}$; IR $\left(\mathrm{KBr}, \mathrm{v}_{\max }, \mathrm{cm}^{-1}\right): 3084,1660,1606 ;{ }^{1} \mathrm{H}$ NMR $\left(\mathrm{DMSO}-d_{6}, 400 \mathrm{MHz}\right): \delta=5.14(\mathrm{~s}, 1 \mathrm{H}, \mathrm{CH}), 7.45-8.18(\mathrm{~m}$, $12 \mathrm{H}, \mathrm{ArH})$; anal. calcd. (\%) for $\mathrm{C}_{27} \mathrm{H}_{13} \mathrm{O}_{5} \mathrm{Br}$ : C 65.21, H 2.63; found (\%): C 65.07, H 2.44.

13-(4-Methylphenyl)-5H-dibenzo[b,i]xanthene-5,7,12,14(13H)-tetraone (Table-1, entry 4). Red powder, m.p. 304-307 ${ }^{\circ} \mathrm{C}$; IR $\left(\mathrm{KBr}, \mathrm{v}_{\max }, \mathrm{cm}^{-1}\right): 3067,1658,1598,1385 ;{ }^{1} \mathrm{H}$ NMR (DMSO- $\left.d_{6}, 400 \mathrm{MHz}\right): \delta=2.19\left(\mathrm{~s}, 3 \mathrm{H}, \mathrm{CH}_{3}\right), 5.09(\mathrm{~s}, 1 \mathrm{H}$, $\mathrm{CH}$ ), 7.07-8.08 (m, 12H, ArH); anal. calcd. (\%) for $\mathrm{C}_{28} \mathrm{H}_{16} \mathrm{O}_{5}$. C 77.77, H 3.73; found: C 77.62, H 3.69.

13-(4-Fluorophenyl)-5H-dibenzo[b,i]xanthene-5,7,12,14(13H)-tetraone (Table-1, entry 5). Brown powder, m.p. 275 $277{ }^{\circ} \mathrm{C}$; IR (KBr, $\left.v_{\max }, \mathrm{cm}^{-1}\right): 3034,1661,1606 ;{ }^{1} \mathrm{H}$ NMR $\left(\mathrm{DMSO}-d_{6}, 400 \mathrm{MHz}\right): \delta=5.09(\mathrm{~s}, 1 \mathrm{H}, \mathrm{CH}), 7.02-8.11(\mathrm{~m}$, $12 \mathrm{H}, \mathrm{ArH})$; anal. calcd. (\%) for $\mathrm{C}_{27} \mathrm{H}_{13} \mathrm{O}_{5} \mathrm{~F}: \mathrm{C}$ 74.31, H 3.00; found (\%): C 74.39; H 2.90.

13-(2-Methoxyphenyl)-5H-dibenzo[b,i]xanthene-5,7,12,14(13H)-tetraone (Table-1, entry 6). Red powder, m.p. 262-265 ${ }^{\circ} \mathrm{C}$; IR $\left(\mathrm{KBr}, \mathrm{v}_{\max }, \mathrm{cm}^{-1}\right): 1675,1604,1591 ;{ }^{1} \mathrm{H}$ NMR (DMSO$\left.d_{6}, 400 \mathrm{MHz}\right): \delta=3.63\left(\mathrm{~s}, 3 \mathrm{H}, \mathrm{OCH}_{3}\right), 5.22(\mathrm{~s}, \mathrm{H}, \mathrm{CH}), 6.85-$ 8.11 (m, $14 \mathrm{H}, \mathrm{ArH})$; anal. calcd. $(\%)$ for $\mathrm{C}_{28} \mathrm{H}_{16} \mathrm{O}_{6}$ : C 75.00, $\mathrm{H}$ 3.60; found (\%): C 74.89; H 3.63.

\section{RESULTS AND DISCUSSION}

In the initial experiments, we investigated the catalytic activities of two heteropolyacids catalysts for the reaction of benzaldehyde with 2-hydroxy-1,4-naphthaquinone under solvent-free conditions at $100{ }^{\circ} \mathrm{C}$. In the course of this study, we found that both can effectively promote the reaction and $\mathrm{H}_{3} \mathrm{PMo}_{12} \mathrm{O}_{40}$ was found to be the more efficient catalyst compared with $\mathrm{H}_{3} \mathrm{PW}_{12} \mathrm{O}_{40}$ (Table-2). The effect of the amount of catalyst was examined in this reaction. The results showed $\mathrm{A}$ $5 \mathrm{~m} \%$ amount of $\mathrm{H}_{3} \mathrm{PMo}_{12} \mathrm{O}_{40}$ was be sufficient to promote
TABLE-2

OPTIMIZATION OF THE REACTION CONDITIONS FOR SYNTHESIS OF 13-PHENYL-5H-DIBENZO[b,i] XANTHENE-5,7,12,14(13H)-TETRAONE

\begin{tabular}{|c|c|c|c|c|}
\hline Entry & Catalyst & $\begin{array}{c}\text { Temp. } \\
\left({ }^{\circ} \mathrm{C}\right)\end{array}$ & $\begin{array}{l}\text { Time } \\
\text { (min) }\end{array}$ & $\begin{array}{c}\text { Yield } \\
(\%)\end{array}$ \\
\hline 1 & $\mathrm{H}_{3} \mathrm{PMo}_{12} \mathrm{O}_{40}(3 \mathrm{~m} \%)$ & 100 & 100 & 77.8 \\
\hline 2 & $\mathrm{H}_{3} \mathrm{PO}_{40} \mathrm{~W}_{12}(3 \mathrm{~m} \%)$ & 100 & 100 & 73.8 \\
\hline 3 & $\mathrm{H}_{3} \mathrm{PMo}_{12} \mathrm{O}_{40}(5 \mathrm{~m} \%)$ & 100 & 100 & 84.3 \\
\hline 4 & $\mathrm{H}_{3} \mathrm{PMo}_{12} \mathrm{O}_{40}(5 \mathrm{~m} \%)$ & 100 & 150 & 85.4 \\
\hline 5 & $\mathrm{H}_{3} \mathrm{PMo}_{12} \mathrm{O}_{40}(10 \mathrm{~m} \%)$ & 100 & 100 & 86.0 \\
\hline 6 & $\mathrm{H}_{3} \mathrm{PMo}_{12} \mathrm{O}_{40}(5 \mathrm{~m} \%)$ & 80 & 100 & 77.4 \\
\hline 7 & $\mathrm{H}_{3} \mathrm{PMo}_{12} \mathrm{O}_{40}(5 \mathrm{~m} \%)$ & 110 & 100 & 84.9 \\
\hline 8 & - & 100 & 100 & Trace \\
\hline
\end{tabular}

the reaction and increased amounts of the catalyst did not lead to any significant changes in the reaction yield. We also studied the model reaction catalyzed by $\mathrm{H}_{3} \mathrm{PMo}_{12} \mathrm{O}_{40}(5 \mathrm{~m} \%)$ at different temperatures. The reaction rate was increased as the reaction temperature was raised, the highest yield was obtained at $110^{\circ} \mathrm{C}$, but the colour of the product changed from red to dark red, which was almost black when it was carried out at $130{ }^{\circ} \mathrm{C}$ and the purification of the reaction mixture at this temperature became more difficult. The reasons for this phenomenon were unclear. Thus, the optimum temperature is $100{ }^{\circ} \mathrm{C}$ for this reaction. Finally, it should be mentioned that when the reactions were carried out without catalyst, almost no conversion occurred.

With this optimized procedure in hand, a range of 13aryl-5H-dibenzo[b,i]xanthene-5,7,12,14(13H)-tetraones was synthesized by the one-pot condensation of aldehydes and 2hydroxy-1,4-naphthaquinone under solvent-free conditions. The reaction proceeded at $100{ }^{\circ} \mathrm{C} \mathrm{ca} .100 \mathrm{~min}$ in excellent yields after the addition of the catalyst $\mathrm{H}_{3} \mathrm{PMo}_{12} \mathrm{O}_{40}(5 \mathrm{~m} \%)$ (Table-1).

To show the merit of the present work, we summarized some of the results for the synthesis of 13-(4-chlorophenyl)-5 H-dibenzo[b,i]xanthene-5,7,12,14(13H)-tetraone obtained by other workers (Table-3). As shown in Table-3, although 2pyrrolidonium hydrogen sulfate and (4-sulfobutyl)tris(4sulfophenyl)phosphonium hydrogen sulfate have high catalytic activity, they are very expensive and the preparation procedures of the two ionic liquid are tedious. So, our method has the advantages of high yield, low cost, simple work-up and environment friendliness comparison with results in the literature.

Although the detailed mechanism of the above reaction remains to be fully clarified, a reasonable possibility is shown in Scheme-II. The reaction proceeded via a reaction sequence of condensation, addition, cyclization and dehydration. First, a proton from heteropolyacid is donated to the oxygen atom of the aldehyde. Next, the carbonyl carbon is attacked by the nucleophilic 2-hydroxy-1,4-naphthaquinone 1 to form orthoquinone methide intermediate $\mathbf{2}$ and it is followed by the protonation and nucleophilic attack of 2-hydroxy-1,4-naphthaquinone giving the intermediate 3 . Subsequent intermolecular interaction leads to cyclic hemiketal $\mathbf{4}$ which on dehydration gives rise to the desired xanthene derivatives 5 . 
TABLE-3

COMPARISON OF THE EFFICIENCIES OF VARIOUS CATALYSTS USED IN THE SYNTHESIS OF 13-(4-CHLOROPHENYL)-5H-DIBENZO[b,i]XANTHENE-5,7,12,14(13H)-TETRAONE

\begin{tabular}{lcccc}
\hline \multicolumn{1}{c}{ Catalyst } & Conditions/T $\left({ }^{\circ} \mathrm{C}\right)$ & Time $(\mathrm{h})$ & Yield $(\%)$ & Reference \\
\hline$p$-TSA & Solvent-free/100 & 2.5 & 80 & 7 \\
{$\left[\mathrm{bmim}^{+}\right]\left[\mathrm{BF}_{4}^{-}\right]$} & Solvent-free/90 & 5 & 86 & 9 \\
TMGT/TFA & Solvent-free/75 & $1-2.2$ & 83 & 10 \\
$p$-TSA & Solvent-free/80 & 7 & 76 & 8 \\
2-Pyrrolidonium hydrogen sulphate/(4-Sulphobutyl)tris(4- & Solvent-free/100 & $0.42 / 0.15$ & $95 / 98$ & 11 \\
sulfophenyl)phosphonium hydrogen sulphate & & & 88 & This work \\
$\mathrm{H}_{3} \mathrm{PMo}_{12} \mathrm{O}_{40}$ & Solvent-free/100 & 1.5 & & \\
\hline
\end{tabular}

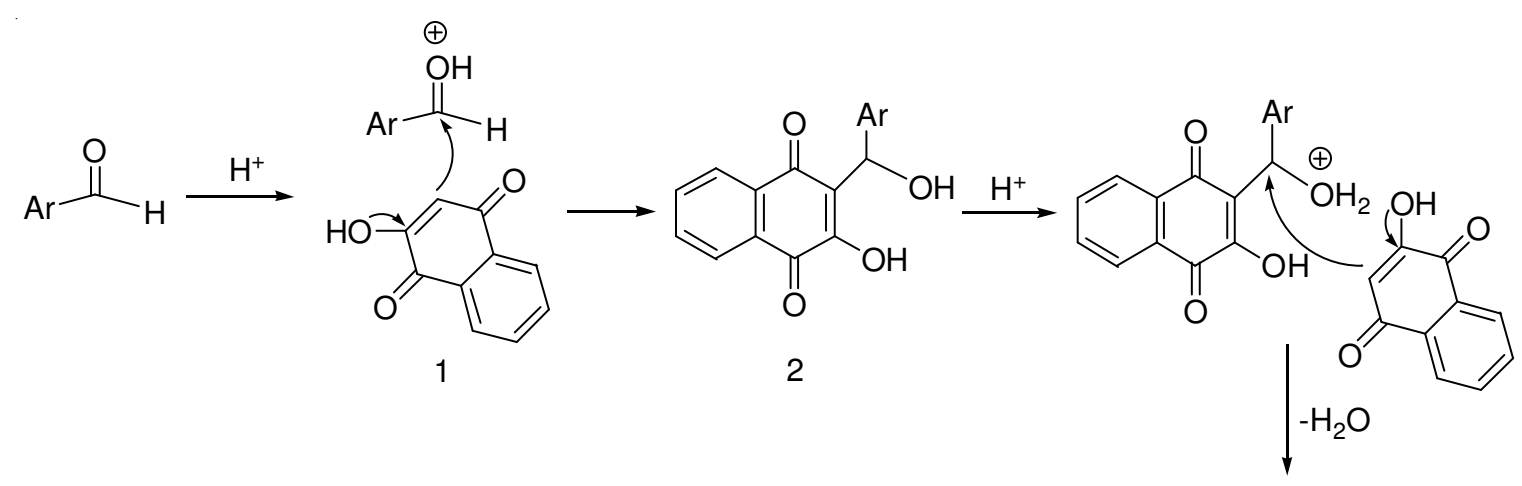<smiles>O=C1C2=C(C(=O)c3ccccc31)C(Br)C1=C(O2)C(=O)c2ccccc2C1=O</smiles>

5<smiles>CC12C(=O)c3ccccc3C(=O)C(O[18OH])(OC3=C1C(=O)c1ccccc1C3=O)C2[Mg]</smiles>

4<smiles>Cc1ccc2c(c1)C(=O)C(C([Al])C1C(=O)C(=O)c3ccccc3C1=O)=CCCCO2</smiles>

3

Scheme-II: Proposed mechanism of the reaction

\section{Conclusion}

This paper describes a convenient and efficient process for the synthesis of 13-aryl-5H-dibenzo[b,i]xanthene$5,7,12,14(13 H)$-tetraones under solvent-free conditions in the presence of $\mathrm{H}_{3} \mathrm{PMo}_{12} \mathrm{O}_{40}$. The attractive features of this protocol are simple procedure, short reaction time, high yields and simple workup. This approach could make avaluable contribution to the existing processes in the field of benzoxanthene synthesis.

\section{ACKNOWLEDGEMENTS}

The authors are thankful to Shandong University of Science and Technology for the partial support of this research.

\section{REFERENCES}

1. M.F. Sartori, Chem. Rev., 63, 279 (1963).

2. M. Behforouz, J. Haddad, W. Cai and Z. Gu, J. Org. Chem., 63, 343 (1998).

3. A.S. Hammam, M.S.K. Youssef, M. Radwansh and M.A. AbdelRahman, Bull. Korean Chem. Soc., 25, 779 (2004).

4. S. Patai and Z. Rappoport, The Chemistry of the Quinonoid Compounds, John Wiley \& Sons. London, England (1988).

5. B.B. Bhowmik and P. Ganguly, Spectrochim. Acta A, 61, 1997 (2005).

6. M. Ahmad, T.A. King, B.H. Cha and J.J. Lee, Phys. D: Appl. Phys., 35, 1473 (2002).

7. Z.N. Tisseh, S.C. Azimi, P. Mirzaei and A. Bazgir, Dyes Pigments, 79, 273 (2008).

8. A. Bazgir, Z.N. Tisseh and P. Mirzaei, Tetrahedron. Lett., 49, 5165 (2008).

9. C. Feng, M.-X. Liu, H.-T. Zhang, C. Wang and J.-J. Ma, Asian J. Chem., 25, 6985 (2013).

10. A. Rahmati, Chin. Chem. Lett., 21, 761 (2010).

11. H.R. Shaterian, M. Ranjbar and K. Azizi, J. Mol. Liq., 162, 95 (2011).

12. I.V. Kozhhevnikov, Chem. Rev., 98, 171 (1998).

13. G.P. Romanelli, D. Bennardi, D.M. Ruiz, G. Baronetti, H.J. Thomas and J.C. Autino, Tetrahedron Lett., 45, 8935 (2004). 